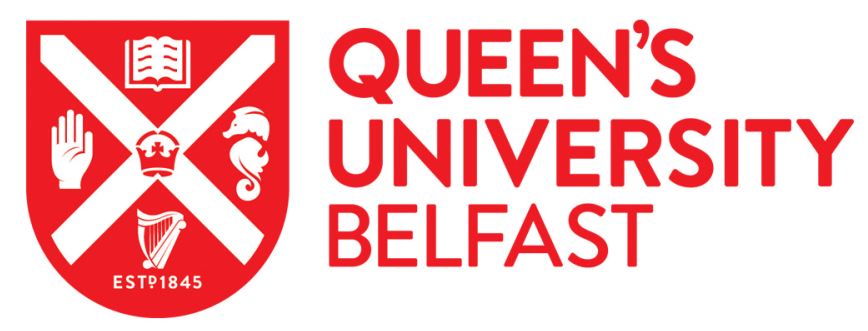

\title{
A qualitative metasynthesis exploring the impact of prostate cancer and its management on younger, unpartnered and gay men
}

Matheson, L., Watson, E. K., Nayoan, J., Wagland, R., Glaser, A., Gavin, A., Wright, P., \& Rivas, C. (2017). A qualitative metasynthesis exploring the impact of prostate cancer and its management on younger, unpartnered and gay men. European Journal of Cancer Care. https://doi.org/10.1111/ecc.12676

Published in:

European Journal of Cancer Care

Document Version:

Peer reviewed version

Queen's University Belfast - Research Portal:

Link to publication record in Queen's University Belfast Research Portal

Publisher rights

Copyright 2017 Wiley. This work is made available online in accordance with the publisher's policies. Please refer to any applicable terms of use of the publisher.

\section{General rights}

Copyright for the publications made accessible via the Queen's University Belfast Research Portal is retained by the author(s) and / or other copyright owners and it is a condition of accessing these publications that users recognise and abide by the legal requirements associated with these rights.

Take down policy

The Research Portal is Queen's institutional repository that provides access to Queen's research output. Every effort has been made to ensure that content in the Research Portal does not infringe any person's rights, or applicable UK laws. If you discover content in the Research Portal that you believe breaches copyright or violates any law, please contact openaccess@qub.ac.uk. 


\title{
Title: A qualitative metasynthesis exploring the impact of prostate cancer and its management on younger, unpartnered and gay men
}

\begin{abstract}
Prostate cancer (PCa) can negatively impact on men’s sexual, urinary and emotional functioning, affecting quality of life. Most men with PCa are older ( $>=65$ years), married and heterosexual and little is known about the impact on men who are younger, unpartnered or gay. We aimed to synthesise existing qualitative research on these three groups of men. A systematic metasynthesis was undertaken that included data on the unique impacts of PCa on younger ( $<65$ years) ( $n=7$ papers), unpartnered ( $n=17$ papers), or gay or bisexual men ( $\mathrm{n}=11$ papers) using a modified meta-ethnographic approach. The three overarching constructs illustrated the magnified disruption to men’s biographies, that included: marginalisation, isolation and stigma- relating to men's sense of being 'out of sync'; the burden of emotional and embodied vulnerabilities and the assault on identity-illustrating the multiple threats to men's work, sexual and social identities; shifting into different communities of practice - such as the shift from being part of a sexually active community to celibacy. These findings suggest that PCa can have a particular impact on the quality of life of younger, unpartnered, and gay men. This has implications for the provision of tailored support and information to these potentially marginalised groups.
\end{abstract}

Key words: prostate cancer, qualitative, metasynthesis, young, LGBT 


\section{Introduction}

Prostate cancer (PCa) is diagnosed in around 1.1 million men worldwide every year, and accounts for $15 \%$ of all male cancers worldwide (World Health Organisation, 2012). In European men, PCa is the most commonly diagnosed cancer and incidence rates are rising (Bray et al, 2010; Cancer Research UK, 2015b). Survival rates are high in countries such as the UK, where $84 \%$ of men can expect to survive for 10 years following diagnosis (Allemani et al, 2015; Cancer Research UK, 2014). The average age at diagnosis in the UK is 71 years and around a quarter of cases arise in men under 65 years old (National Institute For Health and Clinical Excellence, 2014; Public Health England, 2013). PCa treatment can have a detrimental impact on survivors' quality of life as men may encounter problems with sexual, urinary, bowel (Punnen et al, 2015; Watson et al, 2015) and emotional functioning (Bisson et al, 2002; Cliff and MacDonagh, 2000).

There is emerging evidence that particular minority sub groups of men with PCa may exhibit more pronounced needs (Prostate Cancer UK, 2014). First, younger men may perceive PCa as having a greater impact on their lives compared to older age men (BritainThinks, 2014; Prostate Cancer UK, 2014). Exploring younger men’s experiences is particularly important in light of the rising incidence of PCa in younger men, influenced by the increase in prostate specific antigen (PSA) testing (Cancer Research UK, 2015a). Second, men without partners with PCa generally report poorer quality of life, greater unmet needs (BritainThinks, 2014; Dieperink et al, 2012; McCaughan et al, 2013; McSorley et al, 2014) and poorer survival outcomes (Krongrad et al, 1996; Tyson et al, 2013) than partnered men with PCa. Partners of men with PCa play an important role in providing emotional and practical support to the man (Harden et al, 2002; Harden et al, 2006). Therefore the lack of partner support may mean that unpartnered men with PCa are another potentially vulnerable 
'minority’ group with specific needs. Unpartnered status is also rarely a focus of study sampling approaches (Kazer et al, 2011). Thirdly, gay as well as bisexual men with PCa have been shown to have specific needs and concerns after PCa treatment (Amiel et al, 2015; Blank, 2005; Doran, 2015; Prostate Cancer UK and Stonewall, 2013; Smith et al, 2007b; Ussher et al, 2016a). There is evidence that older gay or bisexual men in the general population may be particularly socially isolated and may report issues with their healthcare such as heterosexism, as well as difficulties disclosing their sexual identity (Christina, 2011). The dearth of research on gay or bisexual men with PCa has been noted (Simon Rosser et al, 2016).

Understanding of the diverse range of experiences of these sub groups of men with PCa is important and may indicate ways to reduce inequalities. Qualitative methods can elucidate on experiences but usually use small samples in specific contexts. Synthesizing the findings from multiple qualitative studies to enhance understanding of a substantive area has been shown to be a useful and accepted methodology in health care research (Dixon-Woods et al, 2007a; Dixon-Woods et al, 2001; Wanat et al, 2016). We have conducted a comprehensive metasynthesis of qualitative literature examining the impact of PCa and its treatment on men and their partners following diagnosis (Rivas et al, in preparation). An a priori decision was made to undertake and contrast a subsynthesis focusing on the three relatively understudied groups of younger, unpartnered and gay men. The intention was to draw both on studies that aimed to specifically explore these groups and the many studies that included substantive data specific to these groups despite this not being their primary aim. We aimed to highlight what is currently known from qualitative studies about the unique and shared experiences and needs of these three groups of men and thus 'give voice' to these understudied populations. We have also conducted two separate subsyntheses, reported elsewhere, examining the experiences of men from black or minority ethnic (BME) groups with PCa 
(Rivas et al, In press) and another examining the impact of PCa on couples (Collaço et al, in preparation).

\section{Methods}

Our metasynthesis projects are part of a Prostate Cancer UK and Movember Foundation funded study, ‘Life After Prostate Cancer Diagnosis’ (LAPCD) (University of Leeds and Queen's University Belfast, 2015) and have informed the sampling frame and design of interview topic guides for LAPCD qualitative work. The term 'main synthesis' is used for all data excluding those considered in this subsynthesis on younger, unpartnered or gay men. The full methods for the main synthesis are described in detail elsewhere (Rivas et al, In press; Rivas et al, 2015). Herein we describe the methods relevant to the subsynthesis.

Seven electronic medical, sociological, and psychological databases were searched for articles between $1^{\text {st }}$ January 2000 and $15^{\text {th }}$ December 2015: MEDLINE, CINAHL, PsycINFO, Web of Science, SSCI, AHCI, ProQuest IBSS, with backward and forward citation tracking of all included papers. Grey literature was searched for background information only. The selected timeframe was chosen to reflect changes in treatment regimens and management of PCa from 1997 (National Collaborating Centre for Cancer, 2014) and changes to UK screening guidelines in 2001 (National Screening Committee, 2001; NHS Executive, 2000).

We combined terms for PCa with an adapted version of Saini and Shlonsky's (2012) search strategy, which is a published search strategy for qualitative studies (Suppl file 1). The main synthesis included all men with an established diagnosis of PCa, or their partners /carers (Box 1). The inclusion and exclusion criteria for the main synthesis as well as the additional criteria for the subsynthesis on three sub groups of men were as follows: 


\section{Data extraction and synthesis}

For the main synthesis, the lead reviewer (CR) initially screened titles, which left 711 abstracts (and full texts, where relevant) that were independently assessed for eligibility by CR and LM. Any disagreements were discussed and resolved by third author adjudication (EW/RW). Studies were extracted by the main reviewer (CR) using a standardised data extraction form developed for the study. LM independently extracted a random 25\%, JN extracted 20\% and EW and RW also independently extracted 5\% each, so 55\% of studies were double extracted and compared for any discrepancies. Extractions included publication information, participant demographic and treatment information, study design and full replication of two key sets of constructs (Noblit and Hare, 1988);

- first order constructs; the literal experiences described directly by participants as expressed in verbatim quotes,

- second order constructs; the authors' interpretations and conceptualisation of themes from the data.

Extractions were fully comprehensive and included all relevant and contextual data from the results sections of studies. Background information from each study included in the main synthesis was stored in an Excel database. On a separate Excel spreadsheet, CR, with assistance from LM, developed preliminary lists of first and second order constructs by using raw data such as words from the articles and original terminology of the authors, if possible. All extraction forms were uploaded into Nvivo v.10 software (QSR International Pty Ltd, 2012), a qualitative data management program, which was used as a tool to manage the metasynthesis.

Filters were used to search the Excel database for studies that included groups of men relevant to this subsynthesis. However, key demographic information (e.g. sexuality) was 
not always recorded by studies, or it was sometimes unclear whether any of these three groups of men were discussed in the analysis. Therefore, to ensure all relevant studies were included in the subsynthesis, all study extraction forms were systematically searched for eligibility using Nvivo (QSR International Pty Ltd, 2012), and 'queries’ were as follows;

- young* OR (middle AND age*)

- $\quad$ unpartnered OR single OR widow* OR divorce* OR separated

- gay OR bisexual OR homosexual

\section{Quality assessment}

Quality appraisals of all included studies were conducted by CR, LM and JN using a scoring system adapted by CR from previous published criteria (Cesario et al, 2002; Hannes, 2011). This assessment scored studies on five categories; credibility, methodological congruence (including dependability and confirmability), analytical preciseness, transferability and heuristic relevance or applicability. From total scores, studies were categorised as 'good', 'fair' or 'poor', reflecting the percentage of the total criteria met (75-100\%, 50-74\% or $<50 \%$, respectively). Scores were determined using all publications of a study, some of which are included in the main synthesis but not this subsynthesis. The purpose of quality appraisal was to gather information on the studies, but no poor quality studies were excluded (Dixon-Woods et al, 2007b) as we aimed to be inclusive. However we undertook a sensitivity analysis, whereby poor quality studies were removed from the findings to check the impact of this on constructs.

\section{Data analysis for the three subgroups (younger, unpartnered, gay men)}

A modified form of Noblit and Hare’s (1988) meta-ethnography approach was employed (Britten et al, 2002; Feder et al, 2006; Saini and Shlonsky, 2012). Data analysis began with re-reading of and familiarisation with the original papers and study extraction sheets. All 
relevant extraction forms for all three groups of men were grouped into a separate Nvivo (QSR International Pty Ltd, 2012) folder. First and second order construct data from extraction sheets that were specific to the three groups were organised using Nvivo by LM for each group of men. LM applied reciprocal translation (Saini and Shlonsky, 2012) across different studies for each of the three different groups of men. This process involved assessing whether constructs across studies converged with each other ('reciprocal synthesis') as well as whether there was any divergence, or contradictions between constructs ('refutational synthesis'). This also involved identifying different elements of the topic (a 'line of argument synthesis') (Saini and Shlonsky, 2012). A final set of first and second order constructs (see Table 1) were developed. These were used to develop third order constructs (interpretations of the reviewer). This process involved regular discussion of constructs with the research team, who come from a range of professional backgrounds, including sociology, psychology and nursing. Nvivo software was used to informally assess the volume of reporting of each potential third order construct. Following development of third order constructs from study extraction sheets, the original papers were re-read and cross checked to ensure that third order constructs fully encapsulated the experiences of these groups of men. After examining third order constructs for each of the three groups, overarching conceptualisations or 'lines of argument' (Noblit and Hare, 1988) were constructed for all three groups as a whole.

\section{Results}

In total, 184 articles were included in the main synthesis (Suppl file 2) and of these studies, 131 were inspected for this subanalysis following initial filtering (studies stated that they included one or more of these groups of men). Many papers were then excluded ( $n=105)$ as they did not include specific mention of the impact of being younger, unpartnered, or gay (or 
bisexual) as either a primary aim or through data analysis, or because they did not include any extracts from these groups of men. The subsynthesis included 7 papers relating to younger men, 17 to unpartnered men, and 11 for gay men (one (Thomas et al, 2013) included bisexual men). Twenty-six studies in total were included; seven related to two groups of men (Fergus et al, 2002; Filiault et al, 2008; Hanly et al, 2014; Kelly, 2004; Lee et al, 2015; O'Shaughnessy and Laws, 2009; Ussher et al, 2015), of which all related to gay men and unpartnered men and one study related to all three groups of men (Thomas et al, 2013). While we aimed to look at both gay and bisexual men, of the 11 papers, only one study (Thomas et al, 2013) included a bisexual man (n=1) and another study described their sample as ‘men-who-have-sex-with-men’(MSM) (Lee et al, 2015). Herein, we refer to this group as gay men, unless we are including the paper that had the bisexual man.

A description of all 26 included studies is presented for transparency (Suppl file 3). Two included an explicit subsample of younger men (Chambers et al, 2015; Harden et al, 2006), one recruited only unpartnered men (Kazer et al, 2011), three recruited only gay or MSM samples (Filiault et al, 2008; Hartman et al, 2014; Lee et al, 2015) and one recruited only gay or bisexual men (Thomas et al, 2013). The remaining studies included extracts explicitly stated to be from individuals within these groups, and in general provided small amounts of data. The aims and methods of these studies with minimal extracts varied considerably. Nineteen were interview studies, three employed focus groups, two used a combination, one employed both interviews and observational methods and one used interviews and openended survey responses. The majority of studies were conducted in North America $(n=9)$, Australia ( $n=8)$, or UK ( $n=7)$, and one each conducted in Turkey (Iyigun et al, 2010) and Israel (Eilat-Tsanani et al, 2013) and considered in relation to ethnicities in another of our subsyntheses (Rivas et al, In press). Three papers were part of the same larger mixed methods study (Gilbert et al, 2013; Ussher et al, 2015; Ussher et al, 2013). The 26 studies as 
a group were heterogeneous with regards to the ethnicity and treatment type given to the men included. Studies were identified as good $(n=8)$, fair $(n=17)$ or poor quality $(n=1)$. Removal of the constructs from the poor quality study in sensitivity analysis did not make a difference to the overall findings and it is included without further reference to quality.

\section{Constructs}

The number of studies relating to each $1^{\text {st }}, 2^{\text {nd }}$ and $3^{\text {rd }}$ order construct is presented (see Table 1). Overarching constructs relating to all three groups of men are described below. Exemplar extracts are given throughout, and if authors assigned any demographic information to the participant, these have been added, although the extent to which this level of detail was available was inconsistent across the studies.

\section{1) Younger men}

\section{Being pushed into premature old age: the magnified psychosexual and physical impact}

The side effects of PCa treatment, (including fatigue, incontinence and other effects, as well as the psychosexual impact) could contribute to younger men feeling that their sense of youth was threatened and they were "too young for this” (Chambers et al, 2015) and prematurely pushed into old age (Chambers et al, 2015; Harden et al, 2006; Iyigun et al, 2010; O'Brien et al, 2007). Younger men wished their diagnosis had come later on in life (Harden et al, 2006), and O’Brien et al (2007) reported that men 'felt robbed of natural aspects of masculinity "before its time".

“if it had happened after I retired...it’s much more acceptable” (Harden et al, 2006) (50-64 years)

“I think it's ... the difficulty perhaps in the sexual front is you realize when you get to a certain age, and it varies with individuals, that you are going to lose your sex 
drive. The hard bit I think is having it taken away from you ... maybe ten, twelve or however many years ahead and then it would just occur naturally you know, but the fact that we've had it physically taken away early I think is the hard bit” (O'Brien et al, 2007) (age 60 years)

The psychosexual impact of the disease could have a greater perceived impact, compared to older men, as observed by study authors (Harden et al, 2006; Iyigun et al, 2010). The concept of a magnified psychosexual impact was also found for unpartnered and gay men, discussed later. Younger men found sexuality related changes hard to accept and adjust to as they mourned the loss of their sexual functioning and altered sexual relationships (Chambers et al, 2015; Chapple and Ziebland, 2002; Harden et al, 2006; Iyigun et al, 2010), and reported a lack of understanding over their specific sexuality related issues by the consultant (Chapple and Ziebland, 2002).

"Sex life is a disaster and er you know you can see that you're basically turning into some hermaphrodite status which is you know not very happy, so what do you do? ( . .. ) My NHS consultant was hugely insensitive on these issues. He said 'Oh yes I can see that you're taking on the form of a woman now, it's these drugs, don't worry', you know, in this sort of happy-go-lucky way” (Chapple and Ziebland, 2002) (aged 58 , hormone treatment)

The impact on the men's physicality of fatigue, loss of physical fitness and inability to exercise as they had done before cancer was also particularly hard for younger men to accept (Harden et al, 2006; O'Brien et al, 2007). One author (Harden et al, 2006) observed that, compared to older men, the illness had a greater emotional toll on younger men, including depression. Conversely, younger men in one study also described the positive benefits of their relative youth, in that they felt more optimistic and more likely to overcome the 
disease, and that their greater starting fitness and strength was a contributing factor in their resilience (Chambers et al, 2015).

\section{Being 'out of sync' as a younger man with PCa}

Younger men felt a strong sense of being 'out of sync' with most men with PCa, who they perceived as being significantly older in comparison (Chambers et al, 2015).

"Everywhere I went I was significantly younger than every man in the room, significantly younger. And I just kept saying to my wife, "This just seems just ridiculous," because every single person I was coming into contact with would've been 30 years older than me-25 years to 30 years older. These were guys well into their 70s and maybe into their 80s” (Chambers et al, 2015) (51-60 years)

Men also experienced a sense of separateness to other healthy men their age or in their peer group who were enjoying good health or health issues that were not as serious (Harden et al, 2006).

'I'm the worst one in our group of friends. I think we are all dealing with different health issues, but I'm the only one with cancer.'” (Harden et al, 2006) (50-64 years) This sense of being 'out of sync' also translated into men's perceptions of PCa information which was not felt to be targeted at younger men under 60 years old, shown in one paper of younger gay men (Thomas et al, 2013).

\section{Disrupted identity as a young provider}

Work was a major part of the identities of younger men and they struggled with anxiety and distress over coping with treatment-related side effects that intruded on everyday activities (notably urinary dysfunction) when returning to the workplace (Chambers et al, 2015; Grunfeld et al, 2013). Fears of stigmatisation, the desire to present a strong self as well as 
embarrassment over side effects meant that men were also sometimes reluctant to disclose their problems in the workplace (Grunfeld et al, 2013). Men were very keen to return to work, which was seen as returning to normality (Grunfeld et al, 2013) in one study, in which most participants felt returning to work had been a positive experience. In two other studies, some men reported being unable to work due to poor health and struggled with the subsequent financial impact and disrupted retirement plans (Chapple and Ziebland, 2002; Harden et al, 2006). This could mean that men saw themselves as having disrupted futures.

“I'm only 61, so I'm 9 years from my goal. Now, I can't accomplish that goal. It's impossible. I don't know if I'll ever go back to work again', (Harden et al, 2006) (5064 years)

As well as their role as provider, younger men also struggled to fulfil their perceived role in the home and with their families, often due to fatigue (Grunfeld et al, 2013; Harden et al, 2006), although men in these studies had received a range of treatments which may impact differentially on the severity of fatigue and other side effects compared to some other studies.

\section{2) Unpartnered men}

\section{The shadow over future relationships: retreating from potential intimate partners}

The presence of treatment side effects and the subsequent embarrassment appeared to have 'particular significance’ for unpartnered men, as well as those embarking on new relationships (Kazer et al, 2011). This affected men who wanted casual and also longer term relationships. Unpartnered men (whether heterosexual or gay) were concerned with the perceived shadow cast upon their chances of having future relationships following the changes to their sexual and urinary functioning and body image (Eilat-Tsanani et al, 2013; Fergus et al, 2002; Filiault et al, 2008; Gilbert et al, 2013; Hagen et al, 2007; Lee et al, 2015; 
Letts et al, 2010; Thomas et al, 2013; Ussher et al, 2015). Diminished sexual confidence and a damaged sexual self, coupled with consequential doubts over their current masculinity resulted in some men isolating themselves socially (Fergus et al, 2002; Gannon et al, 2010) and specifically from potential partners, fearing rejection if potential partners were to learn of their sexual dysfunction (Bokhour et al, 2001; Eilat-Tsanani et al, 2013; Gannon et al, 2010; Lee et al, 2015; Thomas et al, 2013; Ussher et al, 2015). They considered they were now unable to engage in spontaneous sexual encounters with casual or new partners, due to embarrassment over sexual dysfunction and urinary leakage as well as the loss of confidence (Bokhour et al, 2001; Eilat-Tsanani et al, 2013; Hanly et al, 2014; Kazer et al, 2011; Lee et al, 2015).

“Because I know I can't do it and I feel inadequate... I am not the same I used to be. I can't perform so I don't go to places where I may meet people...I won't go out socially. I have a lot of friends and I have been invited to go to parties and I said no... which I would have never said before, because I am not sexually active. My social life has changed because of you know... I can't do it anymore and I won't be able to stay the night.” (Gannon et al, 2010) (Age 58 years, radical prostatectomy)

Future committed or long-term relationships could be perceived as an impossibility and men feared not being able to live up to others’ expectations (Bokhour et al, 2001; Fergus et al, 2002; Filiault et al, 2008; Lee et al, 2015; Letts et al, 2010; Thomas et al, 2013) and were concerned over disclosure to new potential partners, which was seen as another hurdle to overcome (Fergus et al, 2002; Gilbert et al, 2013; O'Shaughnessy and Laws, 2009). In heterosexual men, interactions with women were described as nonsexual in that the interactions lacked the potential for sexual intimacy, which was a subtle change following the cancer diagnosis (Bokhour et al, 2001). Unpartnered men held the assumption that future 
partners would not want a man without an erection, and this belief caused them distress (Letts et al, 2010). They exhibited a great deal of embarrassment, awkwardness and shame over erectile issues and the use of sexual aids with new partners (Gilbert et al, 2013; Hanly et al, 2014; Lee et al, 2015).

"I'm afraid to start up with new women because of the inability to have full sexual contact with penetration. I am concerned about it and stay away from it" (EilatTsanani et al, 2013) (age 60 years, radical prostatectomy)

In contrast, one study reported that unpartnered men were more accepting of sexual dysfunction (Grunfeld et al, 2012); however men in this study were aged 78 on average, so this may only be relevant to older unpartnered men. Similarly, a widower more easily accepted the loss of sexual functioning (Kelly, 2004); older and widowed men may have lower expectations of having future sexual relationships.

\section{Reliance on self and non-spousal sources of support}

Partners are often a major source of support for men with PCa, as shown in our related subsynthesis of partner-focussed studies (Collaço et al, in preparation). Unpartnered men lacked this support which may be central to influencing how partnered men managed psychosexual changes post cancer (Gilbert et al, 2013). Unpartnered men had to draw upon alternative sources of support, particularly family and friends (Kazer et al, 2011; Thomas et al, 2013), as well as older adult children or ex partners (Kazer et al, 2011). In one study, unpartnered men particularly relied on the doctor when making decisions about treatment (Kazer et al, 2011). While some unpartnered men found multiple sources of support, others felt unable to talk openly to others and maintained a sense of self-reliance, navigating the cancer journey alone, not wanting to burden others (Kazer et al, 2011; Thomas et al, 2013), as shown below. 
"I began to try to handle things myself so I would say myself was probably the biggest problem. Again, in the beginning I should have gone more to support groups and been with other people who were having the same problem but I guess that was...I call it a private issue. You don't really let them know your business” (Kazer et al, 2011) (49 years old)

In a study of predominately gay unpartnered men, Thomas and colleagues (2013) commented that these men may have much lower levels of perceived support in contrast to the literature on heterosexual (predominately partnered) men. Authors noted that some unpartnered men exhibited a sense of loneliness (Gannon et al, 2010; Kazer et al, 2011; Nanton and Dale, 2011) and widowers, especially those who were older and frail, were observed in one study of BME men to be particularly socially isolated and struggling to navigate the care system (Nanton and Dale, 2011).Whereas, in our related subsynthesis of BME men, partners encouraged men to talk more to others or attend support groups (Rivas et al, In press), which was echoed in our couples subsynthesis (Collaço et al, in preparation), where partners were often the 'communication conduit' between the man and health professional.

\section{3) Gay men}

\section{An invisible self-stigma: disrupted identity within the sexual community}

Gay men felt that the lack of ability to have an erection and ejaculation, as well as reduced libido had a pronounced impact on their sexual identities and masculinity, and confidence in relationships (Filiault et al, 2008; Hanly et al, 2014; Kelly, 2004; Lee et al, 2015;

O'Shaughnessy and Laws, 2009; Thomas et al, 2013; Ussher et al, 2015; Ussher et al, 2013). The prostate gland had been a site of sexual pleasure that was now lost, which was something unique to gay relationships (Filiault et al, 2008) that added to the impact. 
"I always saw my prostate as a pleasure centre" (Filiault et al, 2008).

Similarly, authors commented on the emphasis and importance placed on erections and ejaculations for gay men during sexual encounters (Filiault et al, 2008; Lee et al, 2015) as a contributing factor to the magnified impact. Authors of one study observed that gay men felt a stronger sense of inferiority compared with heterosexual men as their sexual partners were other men with whom they could unfavourably compare their body image or erection problems (Fergus et al, 2002). Due to the often unseen nature of sexual dysfunction, heterosexual and gay men experienced PCa as what Fergus and colleagues (2002) called an “invisible stigma" which was equated by one gay participant with the stigma of HIV. Similarly, men were described as adopting an "internalised stigma" following the impact of treatment in a study of predominately unpartnered gay or bisexual men (Thomas et al, 2013), and the authors stated that this "must be considered in the light of the possibility of the existence of concurrent stigma associated with sexual orientation” (Thomas et al, 2013). Men therefore apparently experienced self-stigma (also known as felt stigma) as opposed to social or public stigma (also known as enacted stigma), which affected their interactions with intimate partners. The authors did not report any unique findings relating to the bisexual participant (Thomas et al, 2013).

\section{Altered sexual practices and roles}

Due to the sexual impact and stigma of PCa, men felt a pronounced sense of being like “damaged goods" (Thomas et al, 2013), especially when interacting with others in the gay community (Fergus et al, 2002; Filiault et al, 2008; Hanly et al, 2014; Kelly, 2004; Lee et al, 2015; O'Shaughnessy and Laws, 2009; Thomas et al, 2013). This was particularly described by unpartnered gay (or bisexual) men who lacked confidence to approach potential partners. 
“For many gay men, if my erection isn't as, not just as long and as big and as fat around, but as prolonged as his, just like if my muscles aren't pumped-my other muscles, my pectorals for example, aren't as pumped as his - then I'm lesser than. And you become lesser, not only lesser male, you become lesser gay I think.” (Fergus et al, 2002)

Similar to heterosexual men (Wittmann et al, 2015), partnered gay men described the disruption to sexual relationships, and couples employed strategies to adjust, such as using sexual aids, becoming more intimate, through verbal and non-verbal communication and non-sexual touching (Hartman et al, 2014; Lee et al, 2015; Thomas et al, 2013; Ussher et al, 2015; Wittmann et al, 2015). These strategies were also shown in our two separate subsyntheses in heterosexual couples (Rivas et al, In press), (Collaço et al, in preparation). Emotional intimacy was enhanced in one gay couple due to the gay partner's empathy from his own experience of erectile difficulties following cancer (Wittmann et al, 2015). As a way of overcoming the strain of sexual dysfunction, open relationships were embraced, as both patients and partners sought alternative sexual partners outside of the relationship (Hartman et al, 2014; Lee et al, 2015), described by a patient below. This way of adjusting to sexual difficulties was described as unique to gay relationships (Hartman et al, 2014; Wittmann et al, 2015), although there was some evidence in our main synthesis that a few heterosexual men offered this (but it was not reported to be taken up by female partners).

"we've got Plan $B[\ldots]$ we do have an open relationship, like in the sense that I've told him point blank that if you need to get fulfilled or whatever, feel free" (Hartman et al, 2014) 
Anal receptive men were less concerned over erectile dysfunction than anal penetrators, and some men switched their sexual role in the relationship, often to becoming anal receptive (Hartman et al, 2014; Lee et al, 2015).

"I found my calling or reinvented myself as a bottom. There's been a lot more anal sex with me receiving since treatment, and my partner is happy with that" (Lee et al, 2015) (62 years old)

\section{Being 'out of sync' with heterocentric health care}

Men described a heteronormative health care bias as clinicians often assumed they were heterosexual, and some men avoided disclosure of their gay (or bisexual) status for fear of judgement by health professionals (Filiault et al, 2008; Lee et al, 2015; Thomas et al, 2013). As one author stated, “this 'closetedness' may have been due to the perception of homophobia in the health care system” (Filiault et al, 2008).

"But, um, he just assumed I was heterosexual and you know, he said, “'Would you like to bring your wife, or . . . to these meetings?'” I mean (A) Was I married? Didn't ask. (B) Was I heterosexual? Didn't ask.” (Filiault et al, 2008)

Men expressed a need for health care professionals who understood the specific issues and needs that gay (or bisexual) men encounter, and recalled the lack of information on and discussion of gay sex (Filiault et al, 2008; Lee et al, 2015; Thomas et al, 2013; Ussher et al, 2013). In one study (Filiault et al, 2008), information given after surgery on sexuality was described by one man as "Victorian" and the authors stated that overall "specific discussions regarding sex did not occur, while the literature provided to patients was not in the least informative nor did it specifically address gay sex”. Overall men noted the lack of gay (or bisexual) specific oncological and psychosocial support and information (Lee et al, 2015; Thomas et al, 2013). 
"We need to have urologists clued up to deal with gay men, we need understanding that our needs and issues are not the same as (those of) a heterosexual man." (Thomas et al, 2013) (age 53 years)

One gay man in this subsynthesis concealed his sexuality in support groups for fear of disapproval from heterosexual men (Lee et al, 2015) and the need for gay (or bisexual) PCa support groups was expressed in one further study (Thomas et al, 2013).

\section{Overarching constructs}

Three overarching constructs (see Figure 1) were developed to capture the shared experiences of the three groups, that is, younger, unpartnered and gay men. These highlight how these men might be distinct from the main body of literature on men with PCa (who are often older, heterosexual and partnered).

\section{Marginalisation, isolation and stigma}

One of the unique characteristics of these three groups of men, in comparison to our main synthesis, was the pronounced sense of stigma, isolation and marginalisation in men's relationships, communities and health care experiences. First, PCa resulted in a subtle and often invisible sense of self-stigma across the groups, as men internalised their feelings of inadequacy. This was influenced by concerns over sexual performance and men's reluctance to disclose about the impact of PCa, particularly to future intimate partners, which seemed to contribute further to their stigmatised sexual and masculine identities. Altogether, this contributed to an underlying sense of marginalisation in these groups of men, who could be particularly socially isolated and 'out of sync' with the majority population of men with PCa, healthy peers, potential intimate partners, existing communities and healthcare provider information. 


\section{The burden of emotional and embodied vulnerabilities and the assault on identity}

In comparison to men in our main synthesis, these three groups of men found it particularly hard to adjust to the psychosexual and physical impact of PCa on emotional wellbeing, sexuality and masculinity, as observed by study authors and expressed by the men themselves. The threat and disruption to men's biographies and identities, especially sexual and work, appeared magnified. While uncertainty and feelings of losing control over the future were evident in our main synthesis, men in these three groups had particular concerns regarding the future. The future was perceived as disrupted due to the acceleration of 'old age’ that was brought on prematurely, affecting their physical strength, sexual ability, capability to fulfil work roles, as well as on existing and future relationships.

\section{Shifting into different communities of practice}

The impact of PCa meant that some men in these groups described shifting into different communities of practice. This could mean a shift from being able to fulfil work roles to premature retirement due to the physical impact of PCa. There was also a shift in some men's social and sexual practices, as they changed from being sexually active to being

celibate, either retreating from the social 'dating' scene or having to adjust to a relationship without sex or a 'different type' of sex. For instance, for gay men specifically, this could mean a shift in sexual practices, from being anal penetrator to anal receiver. This shift into different communities of practice appeared to impact on men's identities, influencing their sense of stigma, as well as the emotional burden of PCa (see Figure 1).

\section{Discussion}

Our metasynthesis highlights the unique impact of PCa on three potentially vulnerable groups of men. There were many similarities with our main synthesis on men with PCa in general (Rivas et al, in preparation), including men’s distress over embodied vulnerabilities 
and changes to their identity, the importance of support from social networks and issues surrounding communication and getting information from the clinician. However, this subsynthesis illustrates that that there are nuances in these themes and a specific and potentially magnified threat to the quality of life of younger, unpartnered and gay men with PCa.

Conceptual commonalities across these groups led to the development of three overarching constructs (Figure 1). Our findings indicate that PCa may present a greater sense of biographical disruption (Bury, 1982) to these three groups of men, due to the burden of emotional and embodied vulnerabilities. We suggest that this contributes to an overall sense of being 'out of sync', similar to Bury’s (1982) concept of 'disrupted feelings of fit' or a sense of difference to their contemporaries, due to the assault on identity. Bury’s (1982) framework has previously been shown to be a relevant concept for men with PCa in general (Cayless et al, 2010; Wenger, 2013), however biographical disruption appears from our study to be pronounced in these groups of men. Across the groups, men exhibited a sense of marginalisation, isolation and stigma. Feelings of self-stigma have been associated with lower quality of life in men with PCa in previous work (Wood, 2015) and were shown in our main synthesis to a degree. Our findings suggest that this may be a pronounced issue for these groups of men, due to either the lack of partner support, life stage and/or sexuality of the man. Across the groups, there was also evidence men were not well supported with these issues and expressed unmet needs regarding age and sexuality appropriate information and support from health professionals. Evidently, as many men belonged to more than one group, it is important that health professionals are aware if men are from these groups, and assess men's needs holistically, taking account of their multiple identities. As suggested by UK policymakers in the National Cancer Survivorship Initiative (NCSI), assessment tools such as the holistic needs assessment may be useful (Young et al, 2015). This will ensure 
that health professionals provide tailored support and information relevant to men's age and life stage, marital status and sexuality.

\section{Younger men}

While our main synthesis clearly indicates that men with PCa report distress over embodied vulnerability, particularly sexual dysfunction, this subsynthesis highlights that younger men may particularly struggle with this impact. The impact of sexual dysfunction also appeared to be pronounced in BME men in our separate subsynthesis, which showed that if the Latino men could remain at work, this compensated for their erectile dysfunction as it maintained their masculine identities (Rivas et al, In press). Our findings echo previous quantitative research indicating that younger men are particularly distressed (Chipperfield et al, 2013), display greater sexuality-related unmet needs (Roberts et al, 2010; Smith et al, 2007a; Weiss Wiesel et al, 2015; Wittmann et al, 2009), perceive a greater impact on their sexual relationships and working lives (BritainThinks, 2014), and are more likely to seek help for sexual problems (Wittmann et al, 2009) compared to older men with PCa. Both authors (Gilbert et al, 2013; Harden et al, 2006) and the men themselves (Chambers et al, 2015; Chapple and Ziebland, 2002; Harden et al, 2006) perceive that the impact of the disease is greater for younger men. Perceptions of when one reaches 'old age' are subjective, but older men have expressed the view that had they been diagnosed at a younger age, it would have been far worse (Bertero, 2001; Chapple and Ziebland, 2002; Maliski et al, 2008; O'Brien et al, 2007). It has been suggested that the effects of treatment such as impotence may be more acceptable to older men who may perceive this as a normal consequence of ageing, or use this normalising as a coping mechanism to reduce the threat to identity (Gannon et al, 2010; Goffman, 1963; Maliski et al, 2008; Scott and Lyman, 1968). 
Few studies in our subsynthesis specifically mentioned younger men's supportive care needs. Those that did indicated that there is a greater need for age relevant information regarding the impact on sexual functioning (Thomas et al, 2013) and that there was a lack of understanding over the sexual impact by urologists (Chapple and Ziebland, 2002), which has implications for care provision. Evaluation of a nurse-led psycho-educational intervention highlighted that younger, more highly educated men with PCa derived greater psychological benefit than older or less well educated men (Chambers et al, 2013). Compared to the other groups, fewer studies in this subsynthesis focused on younger men, and so more research is needed to inform interventions and assess younger men’s preferences for support and information regarding sexuality, work, finances and psychological health. This is especially important since the average age at diagnosis is reducing (Public Health England, 2013). However, men in one study (Chambers et al, 2015) suggest that other factors such as life course (e.g. the presence of a young family, work, fitness, being newly married) are more important than chronological age, as may be factors associated with masculine identity (including sexuality, strength etc.).

\section{Unpartnered men}

A strong theme to emerge in our subsynthesis was the perceived threat to future relationships posed by PCa in unpartnered men (found in heterosexual and gay men), that led them to retreat from potential partners. This is in line with studies on unpartnered men with other types of cancer (Shine Cancer Support, 2013; Zebrack and Isaacson, 2012). Unpartnered men encountered issues surrounding disclosure of their sexual difficulties to future partners. Fears of social rejection due to sexual dysfunction was also particularly noted in BME men in our companion subsynthesis (Rivas et al, In press). Authors of studies included in our current subsynthesis noted that some unpartnered men appeared to have limited social support. In the literature, unpartnered men with cancer have been shown to 
report greater psychosocial problems, greater urinary bother and symptom distress, lower mental health and self-esteem and greater fear of infertility compared to men who are partnered (Fleer et al, 2006; Gore et al, 2005; Tuinman et al, 2010). Relationship status may influence the magnitude of impacts, as partnered men may feel more secure from the threats of cancer on body image, identity, fertility or masculinity, as evidenced elsewhere (Matheson et al, 2016). Identifying men who may be at risk of emotional distress due to social isolation is therefore important. The need for interventions for unpartnered men has been proposed previously (McSorley et al, 2014). While partners have been shown to be a very important source of support for men with PCa (Rivas et al, In press), (Rivas et al, in preparation), it is important to note that a proportion of partnered men may also receive low support (Kamen et al, 2015b) and that unpartnered men may receive sufficient support from other people in their networks. No research examined how these men might want to be better supported, so further research is warranted.

\section{Gay men}

In line with our subsynthesis, quantitative literature shows that gay men with PCa report lower health-related quality of life (Ussher et al, 2016a), more concern over ejaculation difficulties (Ussher et al, 2016a; Wassersug et al), lower masculine self-esteem (Ussher et al, 2016a), worse physical and mental health and poorer satisfaction with care compared to heterosexual men (Hart et al, 2014; Kamen et al, 2015a; Ussher et al, 2016a). As recently shown in a paper published after our search had ended, that supports our findings, gay men may encounter the threat of 'sexual disqualification' (Ussher et al, 2016b), contributing to their feelings of exclusion from the sexual community. Our subsynthesis also highlights the assumed heterosexuality that gay or bisexual men may face when interacting with urologists, echoed recently (Rose et al, 2016), which has implications for health professionals being sensitive to the needs of gay or bisexual men and greater diversity training for urologists. 
Data from these two recent studies (Rose et al, 2016; Ussher et al, 2016b) suggest that our subsynthesis of data on gay men is transferable. The need for information resources specific to gay or bisexual men has been highlighted elsewhere (Prostate Cancer UK and Stonewall, 2013). Gay men were flexible in their approach to sex, similar to heterosexual men in our main synthesis, however gay men embraced open relationships. Whereas, unpartnered gay men lacked confidence to approach future partners, similarly shown in heterosexual unpartnered men. Many studies included unpartnered gay men so more research is needed to explore the experiences of gay men in both monogamous and polygamous relationships, as well as the impact on transgender females with PCa. No studies have exclusively focused on bisexual men and only one study included a bisexual participant (Thomas et al, 2013), so future studies could explore their experiences, as nondisclosure of sexuality to health professionals has been particularly noted in bisexual men (Durso and Meyer, 2013). Our subsynthesis also indicates that the views of older gay or bisexual men with PCa are not adequately explored, and these men may be particularly socially isolated (Christina, 2011). The need for gay and bisexual PCa specific support groups has been shown in one included study (Thomas et al, 2013) and elsewhere (Harris, 2005; Jackson, 2005). However, a lack of good quality intervention studies involving peer support has been noted for men with PCa in general (Chambers et al, 2011). Several support groups for gay, bisexual or transsexual PCa patients have been recently launched in several UK cities (Prostate Cancer UK, 2015), yet these may not be accessible to men living outside these areas. Future studies need to inform novel interventions and resources designed for gay or bisexual men. It is possible that peer support interventions might also be appropriate for unpartnered men.

\section{Limitations and Strengths}

Our subsynthesis has several limitations. First, many studies had minimal relevant extracts, as only a minority specifically focused on any one of these three groups. However, we have 
attempted to draw out the commonalities between studies, and have indicated where data were only relevant to one study. Our main synthesis has enabled us to make comparisons with the wider group of men with PCa and, therefore, highlight what is unique to these three groups of men. This strengthens credibility of our findings given especially that our constructs were not found in other men in the larger body of work considered in our main synthesis. The three groups often overlapped, as men in gay studies were often younger (also noted in quantitative literature (Ussher et al, 2016a)) and unpartnered. This may have increased our sense of commonalities; however the distinct issues each group faced suggests that overall our interpretations are valid. Studies included were heterogeneous in terms of treatment modalities, age ranges, marital status and recruitment and sampling strategies, further strengthening validity and the potential for transferability. In many cases, it was not possible to ascertain the type of treatment received by participants, as this was not often stated next to exemplar extracts. Treatment type may therefore impact on the side effects experienced; influencing our findings, as younger men for instance may be more likely to be treated surgically than with active surveillance (Stangelberger et al, 2008). Most studies did not include prognostic information, so future studies could examine the impact on men from these groups with advanced disease.

The aims of the studies were mixed as examining the impact on these three groups of men was not part of the objectives of many of the authors. This will have affected the types of theme each study reported. It also means we have only been able to include what has been reported, in our attempt to pull together what is known to date on these three groups. The inclusion of studies that exclusively focused on one or more of these groups of men as well as those that had a mixed sample of men including older heterosexual and partnered men has both strengths and limitations. While the mixed studies did not aim to specifically examine the impact of being unpartnered for instance, synthesising the extracts that illustrated this 
resulted in coherent themes. On the other hand, it was not always possible to disentangle the specific impact on these men, as second order constructs (author's interpretations) were aimed at the whole sample. Importantly in terms of credibility, mixed samples meant we were able to examine the authors' interpretations of any differences across their samples, such as observations that younger men in the sample were particularly affected by sexual changes. Studies that focused exclusively on these groups were unable to make firm conclusions about the unique impact on these groups of men.

In addition to the demographic influences (age, sexuality, and marital status) we have explored in this subsynthesis, we acknowledge that many other psychosocial, treatment and disease related variables also impact on adjustment to PCa. Other psychosocial variables and coping strategies, such as positive reframing, illness perceptions, acceptance and normalisation for instance, may be more influential in promoting positive adjustment to cancer compared to demographic factors such as age or life stage, as shown previously (Matheson et al, 2016). In addition, two studies (Filiault et al, 2008; Thomas et al, 2013) that exclusively focused on gay (or bisexual) men employed focus groups, of which these studies and one other (Lee et al, 2015) involved recruitment strategies (e.g. through social media, snowball sampling, support groups etc.) that contrasted with the majority recruitment through hospital clinics. While we aimed to explore the issues for men from a range of sexualities, only one study included a bisexual participant (Thomas et al, 2013), and the authors were therefore not able to comment on any specific issues for bisexual men. Studies were also conducted in a limited range of countries and only a third of studies were good quality. 


\section{Conclusions}

There are many similarities in the experiences of younger, unpartnered and gay men and the wider body of men with PCa. The impact of PCa on quality of life appears, however, to be magnified for these groups. They may experience a unique sense of being 'out of sync' and can feel marginalised from their different community groups, relationships and health care. Health professionals supporting men with PCa need to be aware that men from these groups may require specific information and support regarding the psychosexual, physical, work and relational impact of PCa, relevant to their age and life stage, marital status and sexuality. Health professionals need to explore these issues with men and assess men's personal and social circumstances during clinical appointments, rather than aiming all care at 'the average man with PCa'. Due to a lack of data on the support and information needs of these men, further high quality research is warranted to explore how these men can be better supported. Yet clinicians should not wait for such research; our findings advocate the need for care that is tailored to the needs of the individual. Finding ways of addressing the needs of these groups of men with PCa will help tackle inequalities in their care and experiences.

Conflicts of interest: The authors declare that they have no conflict of interest.

Acknowledgements: This study was funded by Prostate Cancer UK in partnership with Movember (grant number: HO-LAPCD-14-001)

\section{References}

Allemani, C., Weir, H. K., Carreira, H., Harewood, R., Spika, D., Wang, X. S., Bannon, F., Ahn, J. V., Johnson, C. J., Bonaventure, A., Marcos-Gragera, R., Stiller, C., Azevedo e Silva, G., Chen, W. Q., Ogunbiyi, O. J., Rachet, B., Soeberg, M. J., You, H., Matsuda, T., Bielska-Lasota, M., Storm, H., Tucker, T. C., Coleman, M. P. and Group, C. W. (2015). Global surveillance of cancer survival 1995-2009: analysis of individual data for 25,676,887 patients from 279 population-based registries in 67 countries (CONCORD-2). The Lancet, 385 (9972), 977-1010.

Amiel, G. E., Goltz, H. H., Wenker, E. P., Kauth, M. R., Hart, T. L. and Latini, D. M. (2015). Gay Men and Prostate Cancer: Opportunities to Improve HRQOL and 
Access to Care. In: Boehmer, U. and Elk, R. (eds.) Cancer and the LGBT

Community. Netherlands: Springer International Publishing, pp.159-168.

Bertero, C. (2001). Altered sexual patterns after treatment for prostate cancer. Cancer Pract, 9 (5), 245-251.

Bisson, J. I., Chubb, H. L., Bennett, S., Mason, M., Jones, D. and Kynaston, H. (2002). The prevalence and predictors of psychological distress in patients with early localized prostate cancer. BJU international, 90 (1), 56-61.

Blank, T. O. (2005). Gay Men and Prostate Cancer: Invisible Diversity. J Clin Oncol, 23 (12), 2593-2596.

Bokhour, B. G., Clark, J. A., Inui, T. S., Silliman, R. A. and Talcott, J. A. (2001). Sexuality after Treatment for Early Prostate Cancer: Exploring the Meanings of "Erectile Dysfunction”. J Gen Intern Med, 16 (10), 649-655.

Bray, F., Lortet-Tieulent, J., Ferlay, J., Forman, D. and Auvinen, A. (2010). Prostate cancer incidence and mortality trends in 37 European countries: an overview. European Journal of Cancer, 46 (17), 3040-3052.

BritainThinks (2014). Research into the differential needs of men with prostate cancer at different life stages. Available at:

Britten, N., Campbell, R., Pope, C., Donovan, J., Morgan, M. and Pill, R. (2002). Using meta ethnography to synthesise qualitative research: a worked example. $J$ Health Serv Res Policy, 7, 209 - 215.

Bury, M. (1982). Chronic illness as biographical disruption. Sociol Health Ill, 4 (2), 167182.

Cancer Research UK (2014). Prostate cancer survival statistics Available at: http://www.cancerresearchuk.org/cancer-info/cancerstats/types/prostate/survival/ (Accessed: February 17th 2015).

Cancer Research UK (2015a). Prostate cancer incidence statistics. Available at: http://www.cancerresearchuk.org/health-professional/cancer-statistics/statistics-bycancer-type/prostate-cancer/incidence (Accessed: 25th November 2015).

Cancer Research UK (2015b). Prostate cancer statistics. London: Cancer Research UK. Available at: http://www.cancerresearchuk.org/health-professional/cancerstatistics/statistics-by-cancer-type/prostate-cancer (Accessed: December 14th 2015).

Cayless, S., Forbat, L., Illingworth, N., Hubbard, G. and Kearney, N. (2010). Men with prostate cancer over the first year of illness: their experiences as biographical disruption. Supportive Care in Cancer, 18 (1), 11-19.

Cesario, S., Morin, K. and Santa-Donato, A. (2002). Evaluating the level of evidence of qualitative research. JOGNN, 31 (6), 708-714.

Chambers, S. K., Ferguson, M., Gardiner, R. A., Aitken, J. and Occhipinti, S. (2013). Intervening to improve psychological outcomes for men with prostate cancer. Psychooncology, 22 (5), 1025-1034.

Chambers, S. K., Lowe, A., Hyde, M. K., Zajdlewicz, L., Gardiner, R. A., Sandoe, D. and Dunn, J. (2015). Defining Young in the Context of Prostate Cancer. Am. J. Mens Health, 9 (2), 103-114.

Chambers, S. K., Pinnock, C., Lepore, S. J., Hughes, S. and O'Connell, D. L. (2011). A systematic review of psychosocial interventions for men with prostate cancer and their partners. Patient Education and Counseling, 85 (2), e75-88.

Chapple, A. and Ziebland, S. (2002). Prostate Cancer: Embodied Experience and Perceptions of Masculinity. Sociol Health Ill, 24 (6), 820-841.

Chipperfield, K., Fletcher, J., Millar, J., Brooker, J., Smith, R., Frydenberg, M. and Burney, S. (2013). Predictors of depression, anxiety and quality of life in patients with 
prostate cancer receiving androgen deprivation therapy. Psychooncology, 22 (10), 2169-2176.

Christina, H. (2011). Hidden lives: the importance of recognising the needs and experiences of older lesbians and gay men within healthcare practice.

Cliff, A. M. and MacDonagh, R. P. (2000). Psychosocial morbidity in prostate cancer: II. A comparison of patients and partners. BJU international, 86 (7), 834-839.

Dieperink, K. B., Hansen, S., Wagner, L., Johansen, C., Andersen, K. K. and Hansen, O. (2012). Living alone, obesity and smoking: Important factors for quality of life after radiotherapy and androgen deprivation therapy for prostate cancer. Acta Oncol, 51 (6), 722-729.

Dixon-Woods, M., Booth, A. and Sutton, A. J. (2007a). Synthesizing qualitative research: a review of published reports. Qualitative Research, 7 (3), 375-422.

Dixon-Woods, M., Fitzpatrick, R. and Roberts, K. (2001). Including qualitative research in systematic reviews: opportunities and problems. J Eval Clin Pract, 7 (2), 125-133.

Dixon-Woods, M., Sutton, A., Shaw, R., Miller, T., Smith, J., Young, B., Bonas, S., Booth, A. and Jones, D. (2007b). Appraising qualitative research for inclusion in systematic reviews: a quantitative and qualitative comparison of three methods. J Health Serv Res Policy, 12 (1), 42-47.

Doran, D. (2015). The Lived Experience of Gay Men With Prostate Cancer. University of Central Lancashire.

Durso, L. E. and Meyer, I. H. (2013). Patterns and Predictors of Disclosure of Sexual Orientation to Healthcare Providers among Lesbians, Gay Men, and Bisexuals. Sex Res Social Policy, 10 (1), 35-42.

Eilat-Tsanani, S., Tabenkin, H., Shental, J., Elmalah, I. and Steinmetz, D. (2013). Patients' perceptions of radical prostatectomy for localized prostate cancer: a qualitative study. Isr Med Assoc J, 15 (3), 153-157.

Feder, G. S., Hutson, M., Ramsay, J. and Taket, A. R. (2006). Women exposed to intimate partner violence: Expectations and experiences when they encounter health care professionals: a meta-analysis of qualitative studies. Arch Intern Med, 166 (1), 2237.

Fergus, K. D., Gray, R. E. and Fitch, M. I. (2002). Sexual dysfunction and the preservation of manhood: Experiences of men with prostate cancer. Health Psychol, 7 (3), 303316.

Filiault, S. M., Drummond, M. J. N. and Smith, J. A. (2008). Gay men and prostate cancer: voicing the concerns of a hidden population. J Mens Health, 5 (4), 327-332.

Fleer, J., Hoekstra, H. J., Sleijfer, D. T., Tuinman, M. A., Klip, E. C. and Hoekstra-Weebers, J. E. (2006). Quality of life of testicular cancer survivors and the relationship with sociodemographics, cancer-related variables, and life events. Support Care Cancer, 14 (3), 251-259.

Gannon, K., Guerro-Blanco, M., Patel, A. and Abel, P. (2010). Re-constructing masculinity following radical prostatectomy for prostate cancer. Aging Male, 13 (4), 258-264.

Gilbert, E., Ussher, J. M., Perz, J., Wong, W. K., Hobbs, K. and Mason, C. (2013). Men's experiences of sexuality after cancer: a material discursive intra-psychic approach. Cult Health Sex, 15 (8), 881-895.

Goffman, E. (1963). Behavior in public place. Glencoe: the free press, New York.

Gore, J. L., Krupski, T., Kwan, L., Maliski, S. and Litwin, M. S. (2005). Partnership status influences quality of life in low-income, uninsured men with prostate cancer. Cancer, 104 (1), 191-198. 
Grunfeld, E. A., Drudge-Coates, L., Rixon, L., Eaton, E. and Cooper, A. F. (2013). "The only way I know how to live is to work": a qualitative study of work following treatment for prostate cancer. Health Psychol, 32 (1), 75-82.

Grunfeld, E. A., Halliday, A., Martin, P. and Drudge-Coates, L. (2012). Andropause syndrome in men treated for metastatic prostate cancer: a qualitative study of the impact of symptoms. Cancer Nurs, 35 (1), 63-69.

Hagen, B., Grant-Kalischuk, R. and Sanders, J. (2007). Disappearing floors and second chances: men's journeys of prostate cancer. International journal of men's health, 6 (3), 201.

Hanly, N., Mireskandari, S. and Juraskova, I. (2014). The struggle towards 'the New Normal': a qualitative insight into psychosexual adjustment to prostate cancer. BMC Urol, 14, 56.

Hannes, K. (ed.) (2011). Chapter 4: Critical appraisal of qualitative research. Supplementary Guidance for Inclusion of Qualitative Research in Cochrane Systematic Reviews of Interventions. Version 1 (updated August 2011). Cochrane Collaboration Qualitative Methods Group.

Harden, J., Schafenacker, A., Northouse, L., Mood, D., Smith, D., Pienta, K., Hussain, M. and Baranowski, K. (2002). Couples' experiences with prostate cancer: focus group research. Oncol Nurs Forum, 29 (4), 701-709.

Harden, J. K., Northouse, L. L. and Mood, D. W. (2006). Qualitative analysis of couples' experience with prostate cancer by age cohort. Cancer Nurs, 29 (5), 367-377.

Harris, J. (2005). Living with prostate cancer: One gay man's experience. JGLP, 9 (1-2), 109-117.

Hart, T. L., Coon, D. W., Kowalkowski, M. A., Zhang, K., Hersom, J. I., Goltz, H. H., Wittmann, D. A. and Latini, D. M. (2014). Changes in Sexual Roles and Quality of Life for Gay Men after Prostate Cancer: Challenges for Sexual Health Providers. JSM, 11 (9), 2308-2317.

Hartman, M. E., Irvine, J., Currie, K. L., Ritvo, P., Trachtenberg, L., Louis, A., Trachtenberg, J., Jamnicky, L. and Matthew, A. G. (2014). Exploring gay couples experience with sexual dysfunction after radical prostatectomy: A qualitative study. $J$ Sex Marital Ther, 40 (3), 233-253.

Iyigun, E., Ayhan, H. and Tastan, S. (2010). Perceptions and experiences after radical prostatectomy in Turkish men: a descriptive qualitative study. Appl Nurs Res, 24 (2), 101-109.

Jackson, L. (2005). Surviving Yet Another Challenge. JGLP, 9 (1-2), 101-107.

Kamen, C., Mustian, K. M., Dozier, A., Bowen, D. J. and Li, Y. (2015a). Disparities in psychological distress impacting lesbian, gay, bisexual and transgender cancer survivors. Psycho-Oncology, 24 (11), 1384-1391.

Kamen, C., Mustian, K. M., Heckler, C., Janelsins, M. C., Peppone, L. J., Mohile, S., McMahon, J. M., Lord, R., Flynn, P. J., Weiss, M., Spiegel, D. and Morrow, G. R. (2015b). The association between partner support and psychological distress among prostate cancer survivors in a nationwide study. J Cancer Surviv, 9 (3), 492-499.

Kazer, M. W., Harden, J., Burke, M., Sanda, M. G., Hardy, J. and Bailey, D. E. (2011). The experiences of unpartnered men with prostate cancer: a qualitative analysis. Journal of Cancer Survivorship, 5 (2), 132-141.

Kelly, D. (2004). Male sexuality in theory and practice. Nurs Clin North Am, 39 (2), 341356.

Krongrad, A., Lai, H., Burke, M. A., Goodkin, K. and Lai, S. (1996). Marriage and Mortality in Prostate Cancer. J Urol, 156 (5), 1696-1700. 
Lee, T. K., Handy, A. B., Kwan, W., Oliffe, J. L., Brotto, L. A., Wassersug, R. J. and Dowsett, G. W. (2015). Impact of Prostate Cancer Treatment on the Sexual Quality of Life for Men-Who-Have-Sex-with-Men. JSM.

Letts, C., Tamlyn, K. and Byers, E. S. (2010). Exploring the impact of prostate cancer on men's sexual well-being. J Psychosoc Oncol, 28 (5), 490-510.

Maliski, S. L., Rivera, S., Connor, S., Lopez, G. and Litwin, M. S. (2008). Renegotiating masculine identity after prostate cancer treatment. Qual Health Res, 18 (12), 16091620.

Matheson, L., Boulton, M., Lavender, V., Protheroe, A., Brand, S., Wanat, M. and Watson, E. (2016). Dismantling the present and future threats of testicular cancer: a grounded theory of positive and negative adjustment trajectories. J Cancer Surviv, 10 (1), 194205.

McCaughan, E., Mc Sorley, O., Prue, G., Parahoo, K., Bunting, B., Sullivan, J. O. and McKenna, H. (2013). Quality of life in men receiving radiotherapy and neo-adjuvant androgen deprivation for prostate cancer: results from a prospective longitudinal study. J Adv Nurs, 69 (1), 53-65.

McSorley, O., McCaughan, E., Prue, G., Parahoo, K., Bunting, B. and O'Sullivan, J. (2014). A longitudinal study of coping strategies in men receiving radiotherapy and neoadjuvant androgen deprivation for prostate cancer: a quantitative and qualitative study. J Adv Nurs, 70 (3), 625-638.

Nanton, V. and Dale, J. (2011). 'It don't make sense to worry too much': the experience of prostate cancer in African-Caribbean men in the UK. Eur J Cancer Care (Engl), 20 (1), 62-71.

National Collaborating Centre for Cancer (2014). Prostate Cancer: Diagnosis and treatment Available at:

National Institute For Health and Clinical Excellence (2014). Prostate Cancer: Diagnosis and Management (CG175). Available at: http://www.nice.org.uk/cg175 (Accessed: 5th October 2015).

National Screening Committee (2001). Prostate Cancer Risk Management Programme.

NHS Executive (2000). The NHS Prostate Cancer Programme.

Noblit, G. W. and Hare, R. D. (1988). Meta-ethnography: Synthesizing qualitative studies. USA: Sage.

O'Brien, R., Hart, G. and Hunt, K. (2007). "Standing Out from the Herd": Men Renegotiating Masculinity in Relation to Their Experience of Illness. Int J Mens Health, 6 (3), 178-200.

O'Shaughnessy, P. and Laws, T. A. (2009). Australian men's long term experiences following prostatectomy: a qualitative descriptive study. Contemp Nurse, 34 (1), 98109.

Prostate Cancer UK (2014). Men United v Prostate Cancer: Five inequalities, five solutions. Available at: http://prostatecanceruk.org/media/2339836/inequalities-report.pdf

Prostate Cancer UK (2015). Prostate facts for gay and bisexual men. Available at: http://prostatecanceruk.org/prostate-information/living-with-prostate-cancer/gayand-bisexual-men (Accessed: November 25th 2015).

Prostate Cancer UK and Stonewall (2013). Exploring the needs of gay and bisexual men dealing with prostate cancer: A report by Prostate Cancer UK and Stonewall. Available at: http://prostatecanceruk.org/media/1798529/gay_and_bisexual_men_dealing_with_pc report.pdf 
Public Health England (2013). National Cancer Intelligence Network ad hoc information request: Mean and median age at diagnosis (Prostate cancer in England),

Punnen, S., Cowan, J. E., Chan, J. M., Carroll, P. R. and Cooperberg, M. R. (2015). Longterm health-related quality of life after primary treatment for localized prostate cancer: results from the CaPSURE registry. European Urology, 68 (4), 600-608.

QSR International Pty Ltd (2012). NVivo qualitative data analysis Software: version 10.

Rivas, C., Matheson, L., Nayoan, J., Glaser, A., Gavin, A., Wright, P., Watson, E. and Wagland, R. (In press). Special considerations in the treatment and experience of prostate cancer in less studied ethnic group and minority ethnic populations: a qualitative metasynthesis Psychooncology.

Rivas, C., Matheson, L., Wagland, R., Corner, J., Wright, P., Gavin, A., Glaser, A. and Watson, E. (2015). Exploring the quality of life and wellbeing of men with prostate cancer and their partners or carers, and related care needs and gaps in service: protocol for qualitative meta-synthesis. PROSPERO International prospective register of systematic reviews.

Roberts, K., Lepore, S., Hanlon, A. and Helgeson, V. (2010). Genitourinary Functioning and Depressive Symptoms Over Time In Younger Versus Older Men Treated for Prostate Cancer. Annals of Behavioral Medicine, 40 (3), 275-283.

Rose, D., Ussher, J. M. and Perz, J. (2016). Let's talk about gay sex: gay and bisexual men's sexual communication with healthcare professionals after prostate cancer. Eur $J$ Cancer Care (Engl), n/a-n/a.

Saini, M. and Shlonsky, A. (2012). Systematic synthesis of qualitative research. USA: Oxford University Press.

Scott, M. B. and Lyman, S. M. (1968). Accounts. Am Sociol Rev, 33 (1), 46-62.

Shine Cancer Support (2013). Small c project: understanding the needs of adults in their 20's, 30's and 40's with cancer. Available at:

Simon Rosser, B., Merengwa, E., Capistrant, B. D., Iantaffi, A., Kilian, G., Kohli, N., Konety, B. R., Mitteldorf, D. and West, W. (2016). Prostate Cancer in Gay, Bisexual, and Other Men Who Have Sex with Men: A Review. LGBT Health, 3 (1), 32-41.

Smith, D. P., Supramaniam, R., King, M. T., Ward, J., Berry, M. and Armstrong, B. K. (2007a). Age, Health, and Education Determine Supportive Care Needs of Men Younger Than 70 Years With Prostate Cancer. J Clin Oncol, 25 (18), 2560-2566.

Smith, J. A., Filiault, S. M., Drummond, M. J. and Knapman, R. J. (2007b). The psychosocial impact of prostate cancer on patients and their partners. Med J Aust, 186 (3), 159-160.

Stangelberger, A., Waldert, M. and Djavan, B. (2008). Prostate Cancer in Elderly Men. Reviews in Urology, 10 (2), 111-119.

Thomas, C., Wootten, A. and Robinson, P. (2013). The experiences of gay and bisexual men diagnosed with prostate cancer: results from an online focus group. Eur J Cancer Care (Engl), 22 (4), 522-529.

Tuinman, M. A., Hoekstra, H. J., Vidrine, D. J., Gritz, E. R., Sleijfer, D. T., Fleer, J. and Hoekstra-Weebers, J. E. (2010). Sexual function, depressive symptoms and marital status in nonseminoma testicular cancer patients: a longitudinal study. Psychooncology, 19 (3), 238-247.

Tyson, M. D., Andrews, P. E., Etzioni, D. A., Ferrigni, R. G., Humphreys, M. R., Swanson, S. K. and Castle, E. (2013). Marital status and prostate cancer outcomes. Can J Urol, 20 (2), 6702-6706. 
University of Leeds and Queen's University Belfast (2015). Life After Prostate Cancer Diagnosis Available at: http://www.lapcd.leeds.ac.uk/ (Accessed: 30th November 2015).

Ussher, J. M., Perz, J., Gilbert, E., The Australian, C. and Sexuality Study, T. (2015). Perceived causes and consequences of sexual changes after cancer for women and men: a mixed method study. BMC cancer, 15 (268).

Ussher, J. M., Perz, J., Gilbert, E., Wong, W. K. T. and Hobbs, K. (2013). Renegotiating Sex and Intimacy After Cancer Resisting the Coital Imperative. Cancer Nurs, 36 (6), 454-462.

Ussher, J. M., Perz, J., Kellett, A., Chambers, S., Latini, D., Davis, I. D., Rose, D., Dowsett, G. W. and Williams, S. (2016a). Health-Related Quality of Life, Psychological Distress, and Sexual Changes Following Prostate Cancer: A Comparison of Gay and Bisexual Men with Heterosexual Men. J Sex Med, 13 (3), 425-434.

Ussher, J. M., Perz, J., Rose, D., Dowsett, G. W., Chambers, S., Williams, S., Davis, I. and Latini, D. (2016b). Threat of Sexual Disqualification: The Consequences of Erectile Dysfunction and Other Sexual Changes for Gay and Bisexual Men With Prostate Cancer. Arch Sex Behav, 1-15.

Wanat, M., Boulton, M. and Watson, E. (2016). Patients' experience with cancer recurrence: a meta-ethnography. Psychooncology, 25 (3), 242-252.

Wassersug, R. J., Lyons, A., Duncan, D., Dowsett, G. W. and Pitts, M. Diagnostic and Outcome Differences Between Heterosexual and Nonheterosexual Men Treated for Prostate Cancer. Urology, 82 (3), 565-571.

Watson, E., Shinkins, B., Frith, E., Neal, D., Hamdy, F., Walter, F., Weller, D., Wilkinson, C., Faithfull, S., Wolstenholme, J., Sooriakumaran, P., Kastner, C., Campbell, C., Neal, R., Butcher, H., Matthews, M., Perera, R. and Rose, P. (2015). Symptoms, unmet needs, psychological well-being and health status in survivors of prostate cancer: implications for redesigning follow-up. BJU Int.

Weiss Wiesel, T. R., Nelson, C. J., Tew, W. P., Hardt, M., Mohile, S. G., Owusu, C., Klepin, H. D., Gross, C. P., Gajra, A., Lichtman, S. M., Ramani, R., Katheria, V., Zavala, L., Hurria, A. and On behalf of the Cancer Aging Research, G. (2015). The relationship between age, anxiety, and depression in older adults with cancer. Psycho-Oncology, 24 (6), 712-717.

Wenger, L. M. (2013). 'Living under assault': Men making sense of cancer. European Journal of Cancer Care, 22 (3), 389-399.

Wittmann, D., Carolan, M., Given, B., Skolarus, T. A., Crossley, H., An, L., Palapattu, G., Clark, P. and Montie, J. E. (2015). What couples say about their recovery of sexual intimacy after prostatectomy: toward the development of a conceptual model of couples' sexual recovery after surgery for prostate cancer. The Journal of Sexual Medicine, 12 (2), 494-504.

Wittmann, D., Northouse, L., Foley, S., Gilbert, S., Wood, D. P., Jr., Balon, R. and Montie, J. E. (2009). The psychosocial aspects of sexual recovery after prostate cancer treatment. Int J Impot Res, 21 (2), 99-106.

Wood, A. W. (2015). The Influence of Stigma on Quality of Life and Relationship Satisfaction for Prostate Cancer Survivors and Their Partners. University of Central Florida Orlando, Florida.

World Health Organisation (2012). Prostate Cancer Estimate Incidence, Mortality and Prevalence Worldwide in 2012. Available at: http://globocan.iarc.fr/Pages/fact_sheets_cancer.aspx (Accessed: 21th July 2016).

Young, J., Cund, A., Renshaw, M., Quigley, A. and Snowden, A. (2015). Improving the care of cancer patients: holistic needs assessment. Br J Nurs, 24 (4), S17-20. 
Zebrack, B. and Isaacson, S. (2012). Psychosocial Care of Adolescent and Young Adult Patients With Cancer and Survivors. Journal of Clinical Oncology, 30 (11), 12211226. 